\title{
EL PINTOR FLORENTINO FRANCISCO GINETE (CA. 1575-1647): UN ARTISTA CORTESANO ITINERANTE ENTRE MADRID Y ANDALUCÍA
}

\author{
Eduardo Lamas Delgado \\ (Institut royal du Patrimoine artistique (KIK-IRPA) \\ Antonio Romero Dorado \\ (Universidad de Sevilla)
}

\section{RESUMEN}

La revisión de las fuentes publicadas sobre el pintor italiano Francisco Ginete activo en Madrid en la primera mitad del siglo XVII y su confrontación a las conocidas sobre el pintor llamado Francisco Juanete, activo en la corte de los duques de Medina Sidonia en Sanlúcar de Barrameda entre 1604 y 1638 permite concluir que se trata de un solo artista. En ese artículo se establece una primera biografía y se reconstruye su contexto artístico y político para perfilar este pequeño artista cortesano cercano a pintores como Velázquez, Vicente Carducho y Angelo Nardi.

PALABRAS CLAVE: Corte, retrato, España, Diego Velázquez, Lope de Vega.

\section{THE FLORENTINE PAINTER FRANCISCO GINETE (C. 1575-1647): A PERIPATETIC COURTIER ARTIST BETWEEN MADRID AND ANDALUSIA}

\begin{abstract}
The review of the published sources about the Italian painter Francisco Ginete, working in Madrid during the early 17 th century, and about the painter known as Francisco Juanete, working in the service of the Dukes of Medina Sidonia between 1604 and 1638, as well as their confronting, lets to conclude that they were the same person. Consequently, this study offers a first biography about this artists and gathers new and dispersed data that help to define more clearly the figure of a courtesan artist, a close to painters like Velázquez, Vicente Carducho and Angelo Nardi.
\end{abstract}

KEYWORDS: Portrait, court, Spain, Diego Velázquez, Lope de Vega 
En 1625, Lope de Vega dedicaba su libro Virtud, pobreza y mujer al poeta napolitano Giambattista Marino, y en su dedicatoria hacía referencia a un retrato suyo que se había realizado en Madrid por iniciativa del italiano. El autor del retrato era un florentino llamado Francisco Yaneti':

Desde mi amor y inclinación a V. S. justamente tanto favor, que haya tenido deseo de mi retrato; que puesto que la pluma lo es del alma, después de haberla leído en el entendimiento, tengo por honra grande hacer estimación de los exteriores instrumentos; y obediente al Señor Auditor, dejé copiar a los pinceles de Francisco Yaneti, florentín².

Casi olvidado, el tal Yaneti se encuentra, en efecto entre los artistas florentinos instalados en la corte española, conocido en la literatura como Yanete ${ }^{3}$. Anete $^{4}$, Giannetti o Iannetti ${ }^{5}$. Este estudio permite identificar este pintor con otro artista activo en otro contexto geográfico, figura un tanto perfilada recientemente y conocida bajo otra forma castellanizada de su nombre. Se trata del pintor Francisco Juanete, dado a conocer por Cruz Isidoro en un artículo monográfico en $1998^{6}$, y de quien desde entonces se han publicado numerosas obras y noticias que sitúan su actividad en Sanlúcar de Barrameda al servicio de los duques de Medina Sidonia ${ }^{7}$, nobles que se

${ }^{1}$ José Antonio Álvarez y Baena, Hijos de Madrid, ilustres en santidad, dignidades, armas, ciencias y artes, (Madrid: 1790), t. III, 363; Javier Portús, Pintura y pensamiento en la España de Lope de Vega (Hondarribia: 1999), 262-263; Félix Delgado López, "Juan de Baeza y las pinturas de Vicente Carducho en la cartuja del Paular”, Locus amoenus 4 (1998-1999): 185-200, 187; María A. Vizcaíno, El pintor en la sociedad madrileña durante el reinado de Felipe IV (Madrid: FUE, 2005), 456 y 467; David McGrath, "Lope as an icon", en $A$ companion to Lope de Vega, ed. Alexander Samson y Jonathan Thacker (Woodbridge: 2008), 269-284, 280; María A. Vizcaíno, "El círculo de pintores italianos en la corte de Felipe IV", en Centros de poder italianos en la Monarquía Hispánica (siglos XV-XVIII), ed. José Martínez Millán (Madrid: Polifemo, 2010), 17971822, 1811-1812; Clizia Carminati, "Marino e la Spagna nel Seicento", en Il prisma di Proteo. Riscritture, ricodificazione, traduzione fra Italia e Spagna (sec. XVI-XVIII), ed. V. Nider (Trento: 2012), 307-319, 316; Fausta Antonucci, "Virtud, pobreza y mujer (Vega Carpio, Lope Félix de): Dédicace", http:/ /www.idt.paris-sorbonne.fr/html/Vega-Virtud-Dedicace.html (consultado el 20/03/2014).

${ }^{2}$ Lope de Vega, Parte veinte de las Comedias (Madrid: 1627), f. 203r.

3 Vizcaíno, El pintor, 456 y 467; Vizcaíno, "El círculo", 1811-1812.

${ }^{4}$ María del Mar Doval Trueba, Los "velazqueños": pintores que trabajaron en el taller de Velárquez. (tesis doctoral, Universidad Complutense de Madrid, 2003), 420-421.

${ }^{5}$ Portús, Pintura y pensamiento, 209; Elvezio Canonica, "Lope y los literatos españoles en la corte de Felipe III", Anuario Lope de Vega 6 (2000), 61-73, 67.

${ }^{6}$ Fernando Cruz Isidoro, "Francisco Juanete, pintor de cámara de la casa ducal de Medina Sidonia (1604-1638)", Laboratorio de arte 11 (1998), 435-460. Con anterioridad, se había tratado ya sobre Ginete en: Fernando Cruz Isidoro, El santuario de Ntra. Sra. de la Caridad de Sanlúcar de Barrameda (Córdoba: Cajasur, 1997).

${ }^{7}$ Fernando Cruz Isidoro, "Aporte documental al mecenazgo artístico de los VII y VIII Duques de Medina Sidonia", Sanlúcar de Barrameda 42 (2006), 118-136; Fernando Cruz Isidoro, El patrimonio restaurado de la basílica de la Caridad de Sanlúcar de Barrameda (Sanlúcar de Barrameda: ASEHA, 2011); Antonio Urquízar Herrera, "Las casas del desengaño, sus animales, y los límites de las colecciones artísticas de los duques de Medina Sidonia en Sanlúcar de Barrameda", en El duque de Medina Sidonia:

\section{Librosdelacorte.es, PRIMAVERA-VERANO, no 16, año 10 (2018). ISSN 1989-6425 DOI: https://doi.org/10.15366/ldc2018.10.16.004}


encontraban a la cabeza del estado señorial más rico y más poblado de Castilla, que no sólo dominaban amplios territorios de la Baja Andalucía, sino que además ejercía una fuerte influencia sobre Sevilla, Cádiz y Jerez ${ }^{8}$. Por lo demás, el comercio de Sanlúcar de Barrameda, antepuerto de Sevilla y del comercio con América, aportaba pingües beneficios a esta poderosa casa señorial ${ }^{9}$.

El presente artículo reúne por primera vez diversas noticias dispersas que permiten confirmar que el retratista activo en Madrid y el artista cortesano de Sanlúcar fueron, en realidad, una misma persona. Mantendremos aquí para nombrarlo la forma de Francisco Ginete por ser la que él empleó en su testamento y en la única obra firmada localizada hasta hoy, mientras que la de Juanete sólo figura en la documentación administrativa de la corte ducal conservada en Sanlúcar ${ }^{10}$.

Gracias al testamento de Ginete, localizado por Vizcaíno en Madrid, se confirma que el pintor era italiano, y no flamenco como Cruz había sugerido ${ }^{11}$. Ginete nació en Florencia, probablemente hacia $1575^{12}$, y sus padres fueron los ciudadanos florentinos Pedro Jinete y Camila Buenseñor ${ }^{13}$. Ginete debió de llegar a España hacia finales del siglo XVI, donde se casó con la española doña Ana de Mungía, con quien tuvo un hijo llamado igualmente Francisco Ginete ${ }^{14}$. Éste luchó en Lérida en las guerras de Cataluña como ayudante del tercio del general Diego de Villalba y Toledo, mayordomo de Juan José de Austria ${ }^{15}$.

mecenazgo y renovación estética, ed. José Manuel Rico García/Pedro Ruiz Pérez (Huelva: Universidad, 2015), 97-118, 102 y 106.

${ }^{8}$ Luis Salas Almela, The Conspiracy of the Ninth Duke of Medina Sidonia (1641). An aristocrat in the Crisis of the Spanish Empire, Leiden: Brill, 2013, 11 y 14.

${ }^{9}$ Sobre la Casa de Medina Sidonia y su señorío en el siglo XVII, ver Luis Salas Almela, Medina Sidonia: el poder de la aristocracia, 1580-1670 (Madrid: Marcial Pons, 2008).

${ }^{10} \mathrm{Su}$ apellido también aparece en la documentación y en la bibliografía bajo las siguientes formas: Annete, Gianeti, Ginés, Gioaneti, Jamete, Janete, Janet, Janeti, Janeth, Jinete, Joanete, Juanet y Xanete. En cuanto al nombre de pila, en los documentos el pintor suele firmar con la abreviatura Fran. ${ }^{\text {co }}$, válida tanto para Francisco como para Francesco.

11 Madrid, AHP, P. 4842: Testamento de Francisco Ginete, 21-III-1647, ff. 220-223v. Vizcaíno, "El círculo", 1811. Por tanto, el pintor Ginete no presentaría ningún lazo de parentesco con el escultor francés Étienne Jamet (ca. 1510-1565), activo en España bajo el nombre de Esteban Jamete: André Turcat, Etienne Jamet alias Esteban Jamete, sculpteur français de la Renaissance en Espagne condamné par l'Inquisition (Paris: Picard, 1994).

${ }^{12}$ En 1627, Ginete declara tener unos cincuenta y dos años. José M. Cruz Valdovinos, “Aposento, alquileres, alcabalas, aprendices y privilegios (varios documentos y un par de retratos velazqueños inéditos)", en V Jornadas de arte Velárquezy el arte de su tiempo (Madrid 1991), 91-108, 106; Ángel Aterido, Corpus velazqueño: documentos y textos (Madrid: 2000), vol. 1, 65.

13 AHP, P. 4842: f. 220. Probablemente se trata de castellanizaciones de los nombres Pietro Ginette y Camilla Buonsignore. Los apellidos paternos hacen suponer un origen social elevado, y llevan a pensar en el caso de su compatriota Angelo Nardi, descendiente de una familia noble toscana caída en desgracia por obra de los Medici. Sobre este punto: Diego Angulo y Alfonso E. Pérez Sánchez, Pintura madrileña del primer tercio del siglo XVII (Madrid: CSIC, 1969), 271.

${ }^{14}$ Vizcaíno, "El círculo", 1812.

15 AHP, P. 4842, f. 223r. 
Francisco Ginete pudo haber llegado a España atraído por las noticias de la colonia de artistas italianos que Felipe II tenía empleados en la obra del Escorial, donde, como es sabido, trabajaban varios compatriotas suyos con quien lo sabemos relacionado, como veremos más tarde.

Una vez en España, Ginete debió de establecerse primero en la corte de Felipe III, donde entró en contacto con la joven pareja de los condes de Niebla, hijos del VII duque de Medina Sidonia y del duque de Lerma, quienes, recién casados, se instalaron brevemente en Madrid entre noviembre de 1598 y enero de $1599^{16}$. El conde de Niebla, heredero del ducado de Medina Sidonia, era don Manuel Alonso Pérez de Guzmán (1579-1636).

En enero de 1599, ante la sorpresa general, el joven conde decidió abandonar bruscamente la corte real para retirarse a su villa de Huelva, capital oficiosa de su condado. Sin embargo, a finales de ese año, los condes de Niebla regresaron a Madrid. Con la intención de retenerlo allí, Lerma obtuvo para su yerno el título de cazador mayor del Rey y de gentilhombre de su cámara con llave ${ }^{17}$, oficios con los que el valido logró retener a los condes en la corte durante un tiempo, entre Madrid y Valladolid, con algunas jornadas a Huelva ${ }^{18}$. Quizá fue durante esta segunda estancia cuando se produjo el encuentro entre el conde de Niebla y el pintor.

El lazo de Francisco Ginete con los duques de Medina Sidonia ya fue dado a conocer por Cruz en 1996 al publicar un manuscrito del historiador Juan Pedro Velázquez-Gaztelu (1710-1791), archivero de la ciudad de Sanlúcar de Barrameda y administrador de los duques en el siglo XVIII, manuscrito donde se citan los pintores titulados de la Casa ducal ${ }^{19}$. Ahora podemos afirmar que Ginete ya se encontraba al servicio del conde al menos desde 1600, cuando figura en las cuentas de gastos

\footnotetext{
${ }^{16}$ Las capitulaciones matrimoniales se firmaron en el Alcázar de Madrid el 16 de noviembre de 1598; la boda se celebró en el oratorio de la Emperatriz, y el rey actuó de padrino. Salas Almela, Medina Sidonia, 269.

17 Salas Almela, Medina Sidonia, 268. Sobre el funcionamiento de la cámara del rey y sus gentilhombres de llave, ver Santiago Martínez Hernández, "La cámara del rey durante el reinado de Felipe IV: facciones, grupos de poder y avatares del valimiento (1621-1665), in El mundo de un valido: Don Luis de Haro y su entorno, 1643-1661, ed. Rafael Valladares (Madrid: Marcial Pons, 2016), 49-96.

${ }^{18}$ En 1602, la condesa dio luz en Valladolid al futuro IX duque de Medina Sidonia: Salas Almela, Medina Sidonia, 473. Se señala la estancia de Ginete en Valladolid en compañía del conde, pero sin indicar fuentes, en: Cruz Isidoro, "Francisco Juanete".

${ }^{19}$ Juan Pedro Velázquez Gaztelu, Catálogo de todas las personas ilustres y notables de esta ciudad de Sanlúcar de Barrameda, ed. F. Cruz Isidoro (Sanlúcar de Barrameda: ASEHA, 1996), 269. Poco después Bouza hacía referencia a su condición de pintor cortesano a partir de otro manuscrito del historiador: BR, II/573: Juan Pedro Velázquez Gaztelu, Cathálogo de todos los criados mayores y menores que han servido a los excelentísimos duques de Medina Sidonia, sacados por sus respectivos acientos de los libros de acostamientos de la casa, ff. 145r-192v, 50; Fernando Bouza, "Ardides del arte. Cultura de corte, acción política y artes visuales en tiempos de Felipe II”, en Felipe II: un príncipe del Renacimiento (Madrid: 1998), 57-81; Fernando Bouza, Palabra e imagen en la corte. Cultura oral y visual de la nobleza en el Siglo de Oro (Madrid: Abada, 2003), 118.
} 
referidos a los criados de la Casa, entonces establecida entre Madrid y Huelva ${ }^{20}$. En 1603, la contaduría de Niebla ya lo cita "como pintor de esta Casa de su Excelencia"21, mientras que hasta ahora se creía que fue nombrado en $1604^{22}$.

En ese mismo año de 1603 se produjo el abandono definitivo de la corte real por parte de los condes de Niebla, quienes se retiraron de nuevo a sus señoríos hasta poco antes de la muerte del VII duque de Medina Sidonia en $1615^{23}$. Ginete acompañó a sus señores hasta Andalucía, como atestigua un documento inédito de junio de 1607 que señala explícitamente al pintor como responsable de las alhajas en el castillo que los condes de Niebla poseían en Huelva ${ }^{24}$. En 1612 encontramos a Ginete en Sanlúcar trabajando al servicio del padre del conde de Niebla el VII duque de Medina Sidonia, quien falleció poco después. El duque encargó a Ginete la decoración pictórica del recién construido santuario de Nuestra Señora de la Caridad, un ambicioso proyecto artístico culminado en apenas tres años y destinado a ser el lugar de enterramiento del duque y su esposa ${ }^{25}$. En tan sólo doce meses, entre enero de 1612 y enero de 1613, Ginete realizó un total de treinta pinturas ${ }^{26,}$ nueve de ellas destinadas al retablo mayor y otras ocho a los colaterales. El resto era un conjunto de diez lienzos encastrados en los muros de la iglesia, casi todos conservados in situ. En enero de 1612, a la vez que las pinturas de la iglesia, Ginete recibió también el encargo de realizar una vista de una ciudad y dos retratos del duque ${ }^{27}$, uno de los cuales ha sido identificado con el que se conserva en el Palacio ducal de Sanlúcar ${ }^{28}$ (fig. 4).

\footnotetext{
${ }^{20}$ Concretamente, se trata de una referencia a una serie de efectos que se le han entregado en la Casa del conde: « un colchon y un jergon tres sabanas nuevas y dos almohadas y un cobertor blanco que ocupa Fran ${ }^{\text {co }}$ Juanete pintor »: Sanlúcar de Barrameda, Archivo Ducal Medina Sidonia (ADMS), leg. 2710: Cuentas de los Reposteros de Plata, Guarda Ropas, Camareros y demas oficios de la Casa de los Ex.mos S. res Duques de Medinasidon ia é Ynvetarios, de Armas, y Otras Alhajas de dha Casa desde 1587 asta 1606, s.f.

${ }^{21}$ ADMS, leg. 2807: Thesoreria de la Casa de S.E. . Cuentas de los thesoreros Juan de Ocampo de Rueda, don Juan de Aristia y Pedro de Valverde. Año de 1603, s.f.

${ }^{22}$ Cruz Isidoro, "Francisco Juanete", 435.

${ }^{23}$ Salas Almela, Medina Sidonia, 270.

${ }^{24}$ ADMS, leg. 2813: Cuentas de los S.es de la Casa de Medinasidonia con varios particulares desde 1603-b. ${ }^{\text {ta }}$ 1605: Fran ${ }^{c o}$ Juanete en Huelva a 26 de junio de 1607. Cargo de las cosas qe quedan a su cuydado, s.f. Sobre la estancia de los condes en Huelva: Manuel José de Lara Ródenas, "Los muros de Huelva: el conde de Niebla Manuel Alonso Pérez de Guzmán y su retiro en el castillo honubense”, en El duque, 309-310.

${ }^{25}$ Cruz Isidoro, "Francisco Juanete"; Cruz Isidoro, "El santuario". Se ha sugerido que Ginete ya podría haber trabajado para el VII duque en 1605 pintando los lienzos de las tumbas de sus padres los condes de Niebla en el presbiterio de la iglesia de Santo Domingo de Sanlúcar, pero nada permite corroborarlo a día de hoy: Cruz Isidoro, El patrimonio, 84.

${ }^{26}$ Ver el catálogo recogido en Cruz Isidoro, El patrimonio.

${ }^{27}$ Cruz Isidoro, "Francisco Juanete", 444.

${ }^{28}$ Antonio Romero Dorado, "Fuegos artificiales en Doñana para Felipe IV y Olivares: Guzmán el Bueno y la sierpe de Fez: en torno al ideal ético y al repertorio estético de la casa de Medina Sidonia", Cartare, 5 (2015), 31-64, 44.
} 


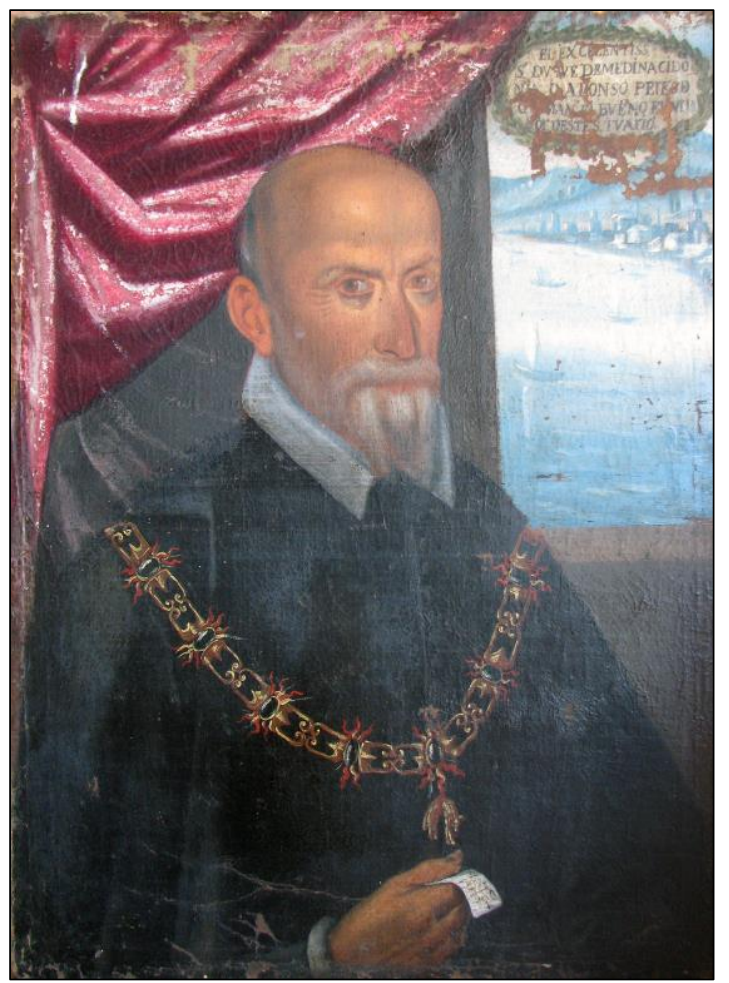

Fig. 4, Francisco Ginete, Retrato del VII duque de Medina Sidonia. 1612, Sanlúcar deBarrameda, Fundación Casa Ducal de Medina Sidonia.

Resulta evidente que Ginete llevó a cabo tan vasta empresa a la cabeza de un equipo de pintores, y en ningún caso en solitario. Aunque pintados con amplia participación de colaboradores, a pesar del mal estado de conservación de muchos de ellos y de la intensa restauración que han sufrido, estos cuadros son la base más firme de que disponemos para conocer el estilo de este artista menor (fig. 1, 2, y 3). Estos cuadros nos muestran a un artista mediocre, pero no exento de interés. Su estilo poco tiene que ver con otros artistas toscanos contemporáneos, a excepción quizá de Cosimo Daddi ${ }^{29}$, y nos habla de una posible formación romana. Así, se aprecia en Ginete un reflejo de la obra de Scipione Pulzone, en la manera de componer, y en ocasiones no pocos elementos próximos a la obra de Giuseppe Cesari, como el tratamiento de los plegados y la forma de dibujar las figuras ${ }^{30}$ (fig. 2). Por su parte, el Tránsito de la Virgen (fig. 1), una de las pinturas del Santuario mejor conservadas, recuerda el cuadro del mismo asunto de Antonio Campi (1523-1587) para la Chiesa di

\footnotetext{
${ }^{29}$ Mariagiulia Burresi \& Franco Alessandro Lessi, Cosimo Daddi: un pittore fiorentino a Volterra (Venezia: Marsilio, 1994).

${ }^{30}$ Eugenio Cajés, compañero de Ginete en Madrid, era también de familia y educación toscanas, y había hecho un viaje de formación a Roma hacia 1595-1599. Aunque se trata de una mera especulación, no es imposible que Ginete hubiera podido coincidir con él allí.
} 
San Marco de Milán. Otras obras, sin embargo, son copias de composiciones más antiguas, posiblemente por deseo del duque, que quizá quiso reproducir algunas de las pinturas devocionales de su colección privada. Así, la Anunciación del retablo mayor copia el icono de la Anunziata en Florencia, cuya devoción era muy popular en los círculos nobiliarios castellanos. En el mismo retablo, la Coronación de la Virgen retoma con variantes una composición de Maarten de Vos, aunque la figura de María encuentra ecos en la de Arpino para la Chiesa Nuova de Roma, mientras que Jesús entre los doctores reinterpreta la composición de Frans Francken el Viejo para su tríptico de la catedral de Amberes, y la Huída a Egipto la de la estampa de Adriaen Collaert a partir de Maarten de Vos. Por su parte, la Adoración de los Magos es una copia del cuadro de Quentin Metsys (1466-1530) del mismo tema conservado en el Metropolitan ${ }^{31}$, una de cuyas versiones pudo haberse encontrado entonces en el oratorio del duque, y éste haberle solicitado copiarla.

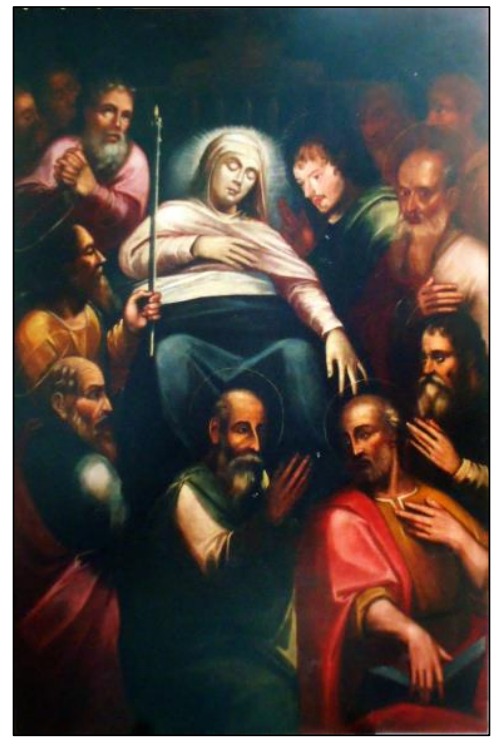

Fig. 1 Francisco Ginete, Tránsito de la Virgen. 1612, óleo sobre lienzo, Sanlúcar de Barrameda, Santuario de la Caridad.

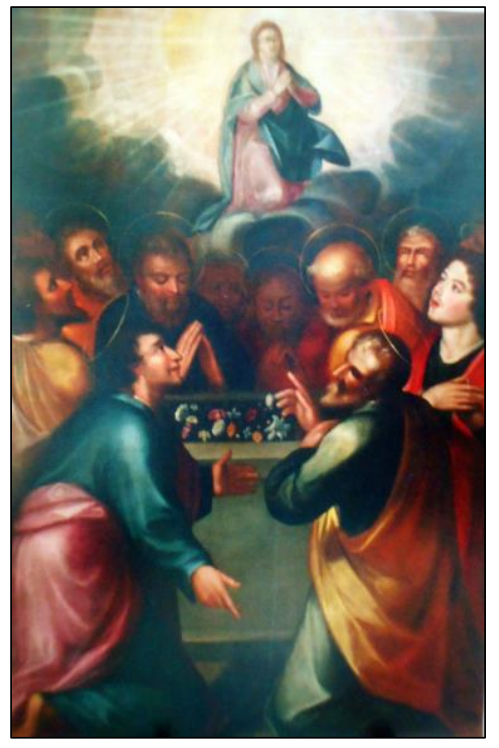

Fig. 2, Francisco Ginete, Asunción. 1612, óleo sobre lienzo, Sanlúcar de Barrameda, Santuario de la Caridad.

\footnotetext{
${ }^{31}$ Quentin Metsys, Adoración de los Magos, 1526, óleo sobre tabla, 102.9 x 80 cm, Nueva York, The Metropolitan Museum, John Stewart Kennedy Fund, 1911 (11.143).
} 


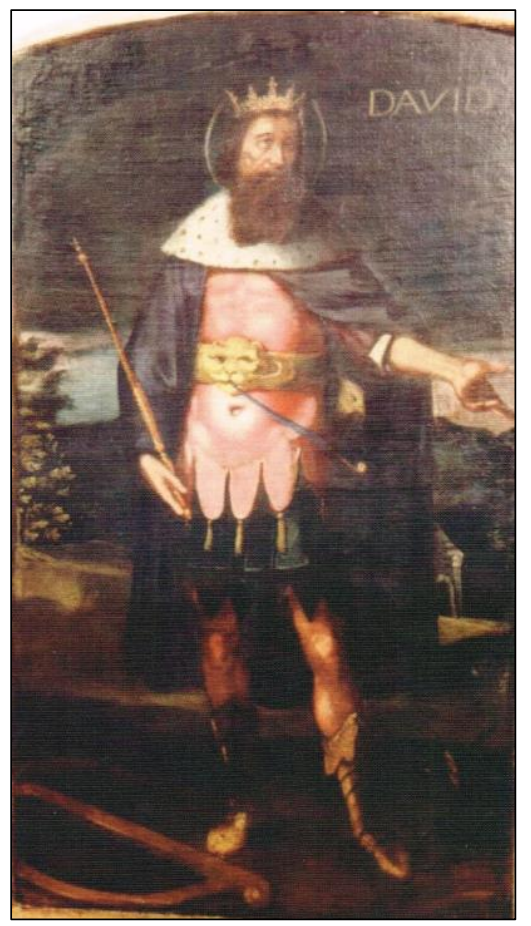

Fig. 3, Francisco Ginete, Rey David. 1612, óleo sobre lienzo, Sanlúcar de Barrameda, Santuario de la Caridad.

En ese mismo año de 1615 fallecía el VII duque. Al heredar el ducado de Medina Sidonia, el conde de Niebla se instaló en el palacio de Sanlúcar y su pintor Ginete pasó a ser criado de la Casa ducal, recibiendo un salario anual de 22.500 maravedíes $^{32}$. Se trataba de un sueldo no muy elevado, pero al que se añadían el pago de las obras realizadas y una ración alimenticia, así como algunas ayudas de $\operatorname{costa}^{33}$.

La iglesia mayor de Sanlúcar, Nuestra Señora de la O, se encuentra junto al Palacio ducal y hacía entonces las veces de capilla palatina, recibiendo numerosas donaciones de los duques y de sus familiares ${ }^{34}$. Por orden del duque, Ginete realizó para esta iglesia un gran lienzo de la Cena en 1617, cuadro destinado a uno de los cuerpos principales del monumento de Semana santa ${ }^{35}$. Se sabe que éste consistía en una estructura de madera dorada y raso carmesí bordado en oro sobre la cual se instalaba

\footnotetext{
${ }^{32}$ Cruz Isidoro, El patrimonio, 82-83.

${ }^{33}$ Fernando Cruz Isidoro, El convento sanluqueño de Capucbinos. Arte e bistoria de una fundación gurmana, (Sanlúcar de Barrameda: ASEHA, 2002), 100.

${ }^{34}$ Antonio Romero Dorado estudia éste y otros aspectos en su tesis doctoral sobre el mecenazgo de los duques en la iglesia de la O de Sanlúcar.

35 ADMS, leg. 2946: Cuentas de los Sres. de la Casa de Medinasidonia con varios particulares. Años 1616 y $1617, \mathrm{n}^{\circ} 13$.
} 
esta pintura ${ }^{36}$. Aquí proponemos identificar este cuadro con el lienzo del mismo asunto y de grandes dimensiones que se conserva en la tribuna del coro de la iglesia (fig. 5) y cuyo estilo se corresponde con las obras conocidas de Ginete ${ }^{37}$.

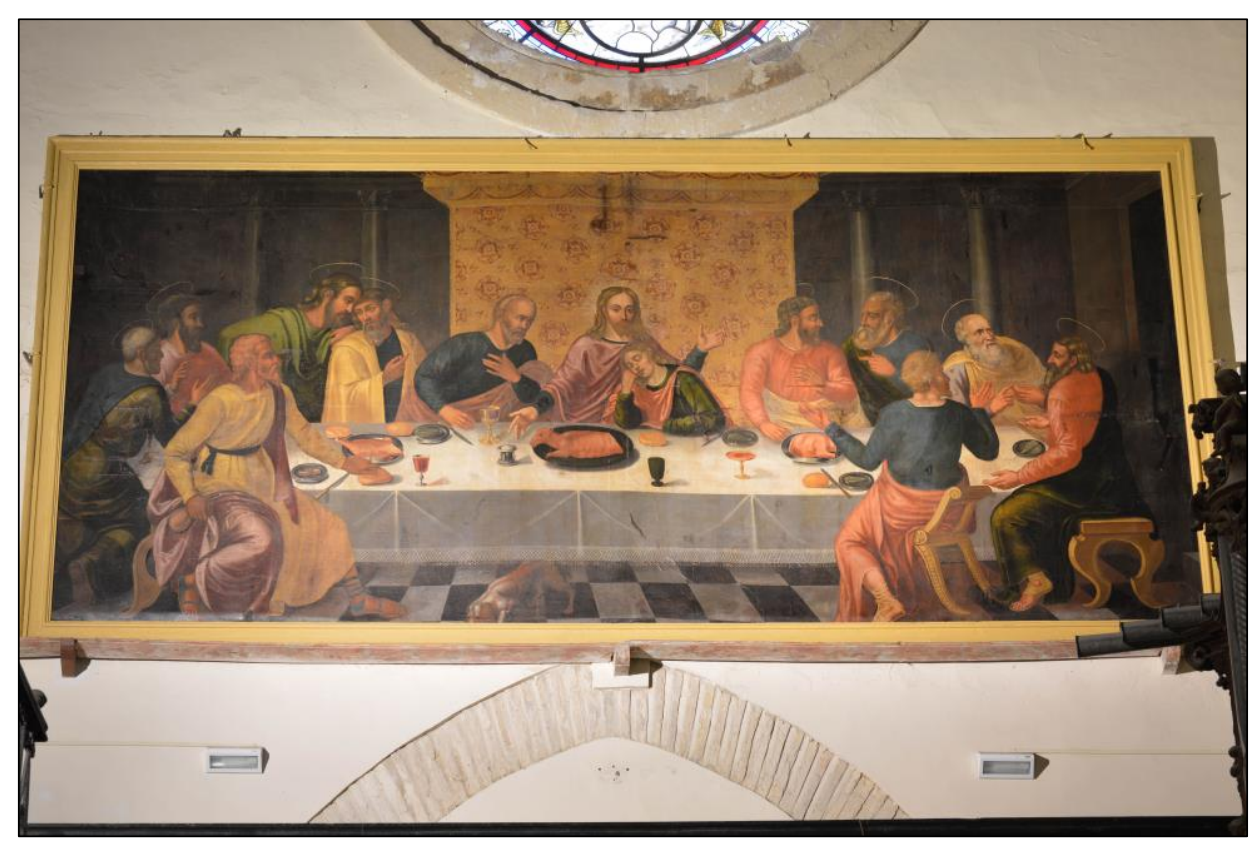

Fig. 5, Francisco Ginete, La Cena. 1613, Sanlúcar de Barrameda, iglesia de Nuestra Señora de la O. (C) A. Romero Dorado

Desde 1621 hasta 1624 no tenemos noticias de Ginete, y a partir de ese año está documentada su presencia en Madrid. Fue entonces, entre 1624 y principios del siguiente, cuando realizó el retrato de Lope de Vega que había encargado Marino, del que se tratará más ampliamente en otro lugar ${ }^{38}$. Los intermediarios del napolitano probablemente encargaron el retrato a Ginete por su condición de italiano, aunque no es imposible que la elección del artista procediese del propio Lope de Vega, muy cercano al círculo de pintores cortesanos, del que Ginete formaba parte. En efecto, varios documentos nos lo muestran bien relacionado con Eugenio Cajés, con Angelo

${ }^{36}$ Juan Pedro Velázquez Gaztelu, Fundaciones de todas las iglesias, conventos y ermitas de la muy noble y muy leal ciudad de Sanlúcar de Barrameda (Sanlúcar de Barrameda: ASEHA, 1995), 66. Cruz Isidoro, "Aporte", 131.

${ }^{37}$ Es reseñable la presencia en el cuadro, en lugar ostensible, de una inscripción en letra del siglo XVIII en la que parece leerse «Carlo Lazare sabre», y que parece una firma apócrifa. Podría responder a la intervención de un restaurador. Romero Dorado trata más ampliamente sobre esta pintura en su tesis doctoral.

${ }^{38}$ Sobre este encargo a Ginete, ver Portús, Pintura, 262-263; Delgado López, "Juan de Baeza", 187; Canonica, "Lope", 67; Antonucci, "Virtud"; Carminati, "Marino", 316. 
Nardi y con Vicente Carducho, además de con Velázquez y su familia. Carducho y Nardi eran florentinos como él, y Cajés, aunque nacido en Madrid, era de familia y educación toscanas.

Sus lazos con la colonia italiana en la corte debieron de ser fundamentales, pero hubo de contar con otros. Al llegar a Madrid, Ginete debió de seguir al servicio del duque de Medina Sidonia a través de su agencia en la Corte ${ }^{39}$. Es muy probable que llevase consigo una carta de recomendación del duque para su hermano don Alonso Pérez de Guzmán, Patriarca de las Indias, capellán y limosnero del Rey, quien le abriría no pocas puertas ${ }^{40}$. Los contactos de los Guzmanes abrieron al pintor las del palacio de la condesa de Miranda del Castañar, fallecida en 1628, y cuya familia presentaba importantes lazos con la del duque ${ }^{41}$. En 1630, Ginete tasó su colección, reunida por su difunto marido el I duque de Peñaranda, virrey de Nápoles entre 1586 y $1595^{42}$. Ese mismo año de 1630, el nuevo conde de Niebla, Don Gaspar, era nombrado gentilhombre de cámara del rey, de modo que Ginete debió de mantener contacto con él en la Corte ${ }^{43}$.

Las relaciones de Ginete en Madrid con los pintores de Palacio, muchos de los cuales eran sus compatriotas, nos son conocidas principalmente a través de tres fuentes, de entre las que destaca la que hace referencia a la tasación que hizo junto a sus compañeros Cajés y Nardi, del ciclo de Carducho para la Cartuja de El Paular, hacia 1632-1633 ${ }^{44}$. Los otros dos documentos son de carácter fiscal. En primer lugar, se trata del pleito de las alcabalas surgido a partir de un censo de los distintos gremios que se hizo entre 1625 y 1638 a raíz de la nueva política recaudatoria del conde-duque de Olivares con el fin de obtener donativos, más o menos forzosos, para asistir a la Corona en el esfuerzo bélico de esos años ${ }^{45}$. En la lista realizada en Madrid en 1625 encontramos a Ginete junto a Velázquez, Francisco Pacheco y Juan de la Corte, así como al arquitecto Pedro de la Torre ${ }^{46}$. Otra fuente relativa a la política fiscal nos presenta a Ginete todavía en Madrid dos años después, siempre en compañía de artistas

\footnotetext{
${ }^{39}$ Luis Salas Almela, "La agencia en Madrid del VIII duque de Medina Sidonia, 1615-1636", Hispania: revista española de historia 227 (2006), 909-958.

${ }^{40}$ Sobre el Patriarca, ver David García López, Lázaro Díaz del Valle y las Vidas de pintores de España (Madrid: FUE, 2008), ${ }^{79-82}$; David García López, “'Dibujo y divina poesía’: Lázaro Díaz del Valle, cronista real, genealogista y dibujante al servicio de Felipe IV”, Goya 333 (2010), 308-319, 311.

${ }^{41}$ Su hijo el segundo duque de Peñaranda estaba casado con la cuñada del duque de Medina Sidonia, doña Francisca de Sandoval y Rojas. Ambos compartían además el señorío de Palos de la Frontera.

42 Getty Provenance Index: E-796. Marcus Burke y Peter Cherry, Collections of paintings in Madrid: 1601-1755 (Los Angeles: Getty, 1997), 1632.

${ }^{43}$ Salas Almela, Medina Sidonia, 309.

${ }^{44}$ Delgado López, "Juan de Baeza”, 186-187 y 198.

${ }^{45}$ Sobre estos pleitos, ver José Manuel Cruz Valdovinos, "El fuero y el huevo: la liberalidad de la pintura: textos y pleitos", en Sacar de la sombra lumbre: la teoría de la pintura en el Siglo de Oro 1560-1724 (Madrid: Abada, 2012), 173-202.

${ }^{46}$ Carmen González Muñoz, "Datos para un estudio de Madrid en la primera mitad del siglo XVII", in Anales del Instituto de Estudios Madrileños 18 (1981), 149-186, 176. Doval Trueba, Los "velarqueños", 420.
} 
cortesanos. Desde 1626, los pintores del gremio y arte madrileños venían desarrollando un pleito contra los arrendadores de impuestos de la Villa de Madrid, que les exigían el pago de un aumento sobre las alcabalas, una tasa que grababa el producto de las ventas pero que, en realidad, nunca se aplicó a los pintores ${ }^{47}$. En el contexto de este pleito, el pintor Juan Velázquez ${ }^{48}$, hermano de Diego, presentó una instancia ante el teniente corregidor de Madrid en representación de todos los demás pintores implicados. El 2 de noviembre de 1627, éste ordenó que se investigase sobre el caso, y para ello se solicitaron los testimonios del propio Velázquez, de Angelo Nardi y de Francisco Ginete ${ }^{49}$.

En ambos documentos, fechados en 1625 y en 1627, Ginete se presenta ante la autoridad como pintor de cámara del Cardenal-Infante Fernando de Austria ${ }^{50}$. No sabemos qué tipo de tareas realizó para él, pero sí que hubo de ejercer el cargo temporalmente, pues también lo ostentaron en algún momento los pintores Andrés López Polanco (ca. 1580-1641) ${ }^{51}$, Pedro de Carvajal y Francisco Gómez de la Hermosa $(\dagger 1656)^{52}$. A Polanco se atribuye un retrato del Infante conservado en el Bowes Museum junto con uno del Infante Don Carlos del que es su pendant. Kusche, que propone fecharlos hacia 1630 , los ha puesto en relación con una serie de retratos de miembros de la Casa de Austria que se encargó a Polanco en 1634 y que incluía ambos retratos, que serían réplicas de éstos ${ }^{53}$. En adelante, será necesario considerar también el nombre de Ginete para futuras atribuciones de retratos de este período.

En 1627, Ginete recibió un aprendiz en su taller de Madrid, un muchacho llamado Ramón Michelet ${ }^{54}$. Este joven era sobrino de Pedro de Michelet, ropero francés natural de Fleurac, en Aquitania, quien acordó ponerlo en casa de Ginete a aprender el arte de la pintura durante cuatro años, en un contrato donde figuraron

\footnotetext{
${ }^{47}$ Cruz Valdovinos, “Aposento”, 98.

${ }^{48}$ Sobre Juan Velázquez, véase: Luis Méndez Rodríguez, "Un pintor ennoblecido: 'la nobleza y lustroso linaje’ de los padres de Velázquez", Laboratorio de arte 12 (1999), 125-134.

${ }^{49}$ Antonio Matilla Tascón, “Comercio de pinturas y alcabalas”, Goya 178 (1984), 180-181. Cruz Valdovinos, "Aposento", 98 y 106; Juan José Martín González, El artista en la sociedad española del siglo XVII (Madrid: Alianza, 1993), 213; Karin Hellwig, “Ut pictura sculptura: zu Velázquez' Porträt des Bildhauers Montañés", Zeitschrift für Kunstgeschichte 3 (1999), 298-319, 319; Aterido, Corpus, I, 65; Doval Trueba, Los "velazqueños", 420.

${ }^{50}$ Juan Luis Blanco Mozo, "Arte, crédito y usura: el pintor Francisco Gómez de la Hermosa y Giovanni Battista Crescenzi", en Il mercato del credito in età moderna. Reti e operatori finanziari nello spaz̧io europeo, ed. E. M. García Guerra y A. de Luca (Milano: 2010), 163-180; Vizcaíno, Elpintor, 313. Vizcaíno, "El círculo", 1811.

${ }^{51}$ Maria Kusche, Juan Pantoja de la Cruzy sus seguidores: B. González, R. de Villandrando y A. López Polanco (Madrid: FAHAH, 2007).

52 Matías Fernández García, Parroquia madrileña de San Sebastián: algunos personajes de su archivo (Madrid: 1995), 158-159. Blanco Mozo, "Arte".

${ }^{53}$ Kusche, Juan Pantoja, 425-429.

${ }^{54}$ Mercedes Agulló Cobo, Noticias sobre pintores madrileños de los siglos XVI y XVII (Granada: 1978), 181. Vizcaíno, El pintor, 453.
} 
como testigos su compañero don Antonio de Peralta, guardarnés del Cardenal-Infante, y el hijo de éste don Tomás de Peralta ${ }^{55}$.

Ginete quizá dejó de servir al Cardenal-Infante en 1632, cuando éste abandonó Madrid rumbo a Bruselas para asumir la jefatura de los Estados de Flandes. En cualquier caso, en 1634 lo encontramos de nuevo en Sanlúcar trabajando al servicio del duque de Medina Sidonia. Allí se ocupó de diversas tareas de decoración y realizó pinturas para el palacio ducal, para la villa suburbana llamada la Huerta del Desengaño y para el vecino convento de Capuchinos ${ }^{56}$, así como de la decoración de pinturas y estucos de la capilla de la Venta de la Berraca, otra residencia de recreo que los duques tenían en el Coto de Doñana, en $1635^{57}$. De ese año es la referencia al pago por parte del duque del alquiler de las casas que habitaba Ginete, propiedad del alférez Melchor de Segura, a quien se debían seis meses de renta ${ }^{58}$.

El 20 de marzo de 1638 murió el VIII duque de Medina Sidonia. Su heredero el conde de Niebla don Gaspar Pérez de Guzmán y Sandoval (1602-1664) se trasladó a Sanlúcar desde Madrid para asumir el gobierno del señorío ${ }^{59}$, y, ese año, confirmó la situación del pintor al servicio de su Casa ${ }^{60}$. Es curioso que en su diccionario de servidores de la Casa ducal, Velázquez Gaztelu dedica al pintor dos entradas distintas, una como criado del VIII duque, con el nombre de Juanete, y otra como criado de su hijo, con el nombre de Ginete ${ }^{61}$. En 1640, el nuevo duque lo nombraba además guardadamas en la corte ducal, con un salario de 200 ducados anuales y la obligación de residir en Palacio, lo que nos habla de la alta estima en que tenía al pintor, junto al que se había criado ${ }^{62}$.

El duque Don Gaspar heredaba también de su padre la Capitanía General del Mar Océano. Por ello, el 20 de abril de 1636 realizó una entrada triunfal en Cádiz, sede de la capitanía, con los ciento veinte jinetes de la compañía de caballería del ducado para reafirmar su poder en la zona, en el contexto de la guerra con Francia que se había declarado el año anterior ${ }^{63}$. Para dar mayor lucimiento a su cortejo, el duque encargó a

55 AHP, P. 5261, ff. 235-236. Agulló, Noticias, 181.

${ }^{56}$ Cruz Isidoro, El convento, 104-105; Cruz Isidoro, El patrimonio, 99; José M. Hermoso y Antonio Romero Dorado, "La Huerta del Desengaño de Sanlúcar de Barrameda: retiro y recreo del VIII duque de Medina Sidonia”, El Rincón malillo 4 (2014), 19-22; Urquízar Herrera, "Las casas”.

${ }^{57}$ Cruz Isidoro, "Francisco Juanete", 451. Juanete también llevó a cabo tareas menores propias de un pintor oficial, como el "pintar las armas de su $\mathrm{ex}^{\mathrm{a}}$ en tres cirios del $\mathrm{s}^{\mathrm{r}}$ duque y mi sa la duquesa y el $\mathrm{s}^{\mathrm{r}}$ conde de Niebla" entre 1637 y 1641, tarea por la que recibe un pago de la fábrica de la parroquia de Nuestra Señora de la O. Ver ADMS, leg. 3119, s.f.; Cruz Isidoro, El patrimonio, 100.

58 ADMS, leg. 3119, s.f.; Cruz Isidoro, El patrimonio, 100.

${ }^{59}$ Salas Almela, Medina Sidonia, 309.

60 BR, II/573: Velázquez Gaztelu, Cathálogo, 50; Bouza, Palabra, 118, n. 54.

61 «GINETE, Francisco (1637). Pintor de cámara del duque D. Gaspar IX por los años de 1637, con ración y 10.000 maravedíes de acostamiento al año »: Velázquez Gaztelu, Catálogo, 204.

62 ADMS, leg. 3165: Manual de la contaduría del Duque mi Sr. Año 1640. 85, f. 127.

${ }^{63}$ Salas Almela, Medina Sidonia, 318-319; Salas Almela, The Conspiracy, 21. 
Ginete la policromía del escudo ducal sobre cuatro trompetas que llevaron sus heraldos ${ }^{64}$.

Tan sólo consta el encargo de una obra por parte del IX duque, una representación de un milagro de la Virgen de la Caridad ocurrido en su santuario de Sanlúcar en 1638, pintura de la que no hemos localizado ninguna otra noticia ${ }^{65}$. Con toda probabilidad, la pintura se colocó en el patio del Hospital de San Pedro donde consta que hacia 1612-1614 figuraba una colección de pinturas al óleo con representaciones de milagros obtenidos por mediación de la imagen ${ }^{66}$.

En esos años, Ginete realizó también un cuadro del arcángel san Miguel por encargo del Ayuntamiento de Sanlúcar ${ }^{67}$. La última referencia que se tiene de su presencia en la ciudad es precisamente el acta de un cabildo de 15 junio de 1643, cuando se acuerda colocar el cuadro en el salón de plenos y entregar al pintor los ochenta reales que se habían acordado como pago ${ }^{68}$. Con este encargo, el Ayuntamiento respondía al voto a san Miguel como patrón de la Monarquía que se hizo ese mismo año, y a una carta del Consejo de Castilla solicitando a todas las ciudades dedicar fiestas al santo para invocar su protección sobre el reino ${ }^{69}$.

\section{EL RETORNO DEFINITIVO A MADRID: EL PINTOR DE UN SEÑOR CAÍDO EN DESGRACIA}

Probablemente el encargo del Ayuntamiento fue la última obra de Ginete en Sanlúcar, donde acababa de producirse un verdadero terremoto político que acabaría

\footnotetext{
${ }^{64}$ Este trabajo fue retribuido a Ginete el 28 de abril de 1636. En agosto de ese año se le encargó el barnizado de una de las carrozas del duque. ADMS, leg. 3127, f. 65v; Cruz Isidoro, El patrimonio, 100. Entre 1637 y 1641 se debe de situar otro pequeño dato sobre sus labores al servicio de Don Gaspar: "pintar las armas de su ex en tres cirios del s $\mathrm{s}^{\mathrm{r}}$ duque y mi sa la duquesa y el s $\mathrm{s}^{\mathrm{r}}$ conde de Niebla", por que recibe un pago a través de la fábrica de la parroquia de Nuestra Señora de la O: Jerez de la Frontera, Archivo Histórico Diocesano, Parroquia de Nuestra Señora de la O. Sanlúcar de Barrameda. Fondo Parroquial. V. Fábrica. 6. Visitas: Libro de visitas (1637-1645), f. 251v.

${ }^{65}$ Por esta obra se registra un pago de 24 reales en septiembre de 1638: ADMS, leg. 3147, f. 165v. En otro lugar se ha afirmado, basándose en esta fuente, que se trataba de un conjunto de pinturas murales realizado en el patio del Hospital de San Pedro de Sanlúcar en colaboración con un pintor llamado Giles Gilberto, pero ninguna de estas informaciones figura en el documento: Cruz Isidoro, El patrimonio, 99.

${ }^{66}$ BNE, Mss /188: Pedro Beltrán, La Caridad gurmana, ff. 427v-449v.

${ }^{67}$ Velázquez-Gaztelu, Fundaciones, 512; Cruz Isidoro, El patrimonio, 100.

${ }^{68}$ Sanlúcar de Barrameda, Archivo Municipal (AMS), Sig. 4717: Actas capitulares de los años 1643-1645, libro 16, f. 45v. En el documento se recoge un segundo pago por haber pintado (“dado de color") los espaldares de los escaños de la sala de juntas. No obstante, debemos señalar que en el documento se recoge el nombre del pintor como Juan Juanete, lo que atribuimos a un error.

69 AMS, Sig. 4717, ff. 10-12. Para el voto a san Miguel, ver: Cécile Vincent-Cassy, "Saint Michel et la Monarchie Hispanique : l'invocation de la protection angélique en 1643", en Des saints d'Etat : politique et sainteté au temps du concile de Trente, ed. Florence Buttay y Axelle Guillausseau (Paris: Presses de l'Université de Paris-Sorbonne, 2012), 89-103.
} 
con la corte ducal. El duque se hallaba implicado en una conspiración que tenía como objetivo la sublevación de los reinos andaluces, y en agosto de 1642 había sido arrestado y conducido preso al castillo de $\mathrm{Coca}^{70}$. Aunque en un principio el duque obtuvo el perdón real, poco después la manera en que se estaba desarrollando la crisis de Portugal y de Cataluña llevó al rey a endurecer su actitud ${ }^{71}$. La duquesa y su familia recibieron orden real de abandonar el palacio de Sanlúcar y encontraron refugio con sus padres los marqueses de Priego, en su palacio de Puente Genil ${ }^{72}$. En diciembre de 1643, la duquesa se trasladó a Madrid con el conde de Niebla para tratar de defender el caso de su marido en la Corte y obtener la clemencia del rey ${ }^{73}$. Hasta allí les acompañaron, como es natural, sus familiares, y entre ellos el guardadamas Ginete. Una vez en Madrid, la duquesa pagó al pintor por dos pinturas que enviaba a su madre: "una con la Ymagen del Salvador y otra con la de Nra Señora para remitir a mi señora la Marquesa de Priego" ${ }^{74}$. Se trataba probablemente de un regalo en agradecimiento de la acogida que le hicieron sus padres cuando debió abandonar Sanlúcar precipitadamente $^{75}$.

Proponemos poner este encargo en relación con un icono de la Virgen fechado en 1644 y firmado por Ginete que se encontraba en la clausura del convento de Santa Ana en Córdoba en $1904^{76}$. Patronato de los marqueses de El Carpio, este convento podría haber adquirido el cuadro con posterioridad, quizá por vía de un donativo realizado más tarde por la marquesa o por algún pariente suyo ${ }^{77}$. El hecho de que esta obra sea la única de Ginete de cuya firma se tiene constancia podría estar en relación con la voluntad del artista de hacerse valer ante la corte de los marqueses de Priego, ante la precariedad de su situación como criado de la Casa ducal.

Como ha señalado Salas, el período que siguió al arresto del duque y a la salida de la familia ducal de Sanlúcar fue de una gran incertidumbre ${ }^{78}$. La situación provocó la bancarrota de las finanzas ducales. Para ganarse la voluntad del rey, el duque hubo

\footnotetext{
70 Salas Almela, Medina Sidonia, 379.

${ }^{71}$ Salas Almela, Medina Sidonia, 363.

72 Salas Almela, Medina Sidonia, 378. Doña Juana Fernández de Córdoba, duquesa de Medina Sidonia, era hija del V marqués de Priego.

${ }^{73}$ Salas Almela, The Conspiracy, 139.

${ }^{74}$ ADMS, leg. 3194: Thesoreria de la Casa de S. E. Cuentas del Liz: do Diaz Christobal Deza, Alonso Asensio, Fran. ${ }^{c o}$ del Real Hern. ${ }^{d o}$ Diaz, Miguel del Barco, D." Antt. de Castro, y Alonso de Rueda de los años 1643 y 1644. Tom. 123, f. 317.

${ }^{75}$ Salas Almela, Medina Sidonia, 378

${ }^{76}$ Rafael Ramírez de Arellano, Inventario monumental y artístico de la provincia de Córdoba (Córdoba: Diputación Provincial, 1983), 193. El autor recoge la firma del cuadro con un error evidente en la transcripción de la fecha: « Francisco Ginete me fecit.1544 ».

${ }^{77}$ La sobrina de los marqueses de Priego, doña Catalina Fernández de Córdoba y Aragón, hija del V duque de Segorbe, casó con don Luis de Haro y Guzmán, VI marqués del Carpio. Una hija de éstos, doña Antonia de Haro, fue consorte del X duque de Medina Sidonia. Estas relaciones familiares podrían explicar la llegada del cuadro al convento cordobés.

${ }^{78}$ Salas Almela, The Conspiracy, 143.
} 
de incurrir en numerosos gastos en forma de servicios y donativos al servicio real ${ }^{79}$, y además se le impidió la gestión directa del señorío de Sanlúcar, el pilar económico de la Casa, que se puso bajo la administración del Consejo de Estado y de la Junta Grande $^{80}$. En agosto de 1645, se decidió incorporar el señorío de Sanlúcar a la jurisdicción real, mandándose eliminar los escudos ducales de los edificios públicos y del palacio ${ }^{81}$. Finalmente, el duque fue desterrado a Valladolid; en 1647, el año de la muerte de Ginete, la situación era tan desesperada que Medina Sidonia se vio obligado a vender una serie de propiedades vinculadas a su mayorazgo ${ }^{82}$.

Probablemente, el desbarato económico de la Casa ducal impidió mantener en nómina un pintor de cámara. Lo cierto es que la documentación nos sitúa a Ginete en 1646 como maestro independiente en Madrid, donde se declara estante, no vecino ${ }^{83}$. Ginete había instalado su obrador en un cuarto que tenía alquilado en casas del boticario Luis de Saldaña en Madrid, en la plazuela de Santo Domingo ${ }^{84}$. Allí contaba con la ayuda de un aprendiz que quizá trajo con él de Sanlúcar: Gregorio Carballo Pacheco $^{85}$. Aunque había conseguido pronto una nueva clientela, sobre todo como retratista, Ginete no tardó en tener problemas para hacer frente a sus gastos ${ }^{86}$. Los pagos por sus obras no le llegaban con la puntualidad necesaria; aún se le debían buena parte de las pinturas que había realizado hasta entonces para varios particulares. Se trataba principalmente de retratos, que conocemos gracias al inventario de su taller realizado a su muerte ${ }^{87}$. Además, tenía deudas con tres acreedores: Don Juan Cejudo, el capitán Don Gregorio Gabriel Carrillo ${ }^{88}$, que le había hecho un préstamo, y una criada del Patriarca.

\footnotetext{
${ }^{79}$ En 1641, el duque ofrece al rey un destacamento de caballería para la lucha en la frontera aragonesa. Es muy posible que en él fuese el hijo de Francisco Ginete, que como hemos visto, se hallaba en 1646 luchando en Lérida. Estos méritos, junto con el recuerdo de los de su padre, valieron años más tarde a Francisco Ginete hijo el gozar del favor del duque, quien, hacia 1652, le nombró caballerizo mayor con ración y sueldo de 49.940 maravedíes de acostamiento al año: Velázquez-Gaztelu, Catálogo, 204. Hacia ese fecha, la situación económica de la Casa ducal se estabilizó en la pequeña corte que el duque mantuvo durante su exilio en Valladolid.

${ }^{80}$ Salas Almela, The Conspiracy, 138.

${ }^{81}$ Salas Almela, The Conspiracy, 141.

82 Salas Almela, The Conspiracy, 149.

83 AHP, P. 4842, f. 220r.

${ }^{84}$ AHP, P. 4842, f. 221v.

${ }^{85}$ AHP, P. 4842, f. 222v. Es posible que este aprendiz marchase después a América y que se le pueda identificar con el pintor Gregorio Carballo de la Parra (†1667) activo en la Nueva Granada: Fernando Arellano, El arte hispanoamericano (Caracas: 1988), 372.

${ }^{86}$ AHP, P. 4842, f. $221 \mathrm{r}$.

87 AHP, P. 4842, f. 220v-221v.

${ }^{88}$ Este personaje, caballero de Alcántara, fue condenado a muerte en 1651: Elena Postigo Castellanos, Honor y privilegio en la Corona de Castilla: el Consejo de Ordenes y los caballeros de hábito en el s. XVII (Valladolid: 1988), 162.
} 
En este último periodo de su vida en Madrid lo encontramos en relación con varios artistas. Así, sabemos que compró un cuadro a Antonio de Puga (1602-1648) ${ }^{89}$ y de su relación de amistad con Santiago Morán II $^{90}$. También era amigo de un tal Don Juan de Somarriba, que proponemos identificar con el matemático homónimo, autor de un tratado científico ${ }^{91}$.

Ginete murió arruinado el 22 de marzo de 1647, siendo enterrado en la iglesia parroquial de San Martín ${ }^{92}$. El día anterior se encontraba enfermo y en cama e hizo testamento, dejando a su hijo como heredero universal ${ }^{93}$. A su discípulo Gregorio Carballo le concedió los pinceles y colores del taller, así como parte de sus dibujos y sus estampas, lamentando no poder dejarle más "por la mucha voluntad que le tiene" Los albaceas del testamento fueron Somarriba y Morán, quienes hicieron tasar sus bienes, únicamente muebles, para proceder a celebrar una almoneda pública con cuyo fruto satisfacer sus deudas y pagar su entierro. Para las pinturas designaron como tasadores a los pintores Domingo Yanguas y Bartolomé Román (†1647). Román, era discípulo de Carducho y podía haber entrado en relación con Ginete y su círculo por esa vía. El otro tasador de los bienes, Yanguas, también gravitaba en torno a la corte ${ }^{95}$; había trabajado para el Buen Retiro y para entradas reales y era además alguien cercano a Velázquez, con quien sabemos que también Ginete estaba en contacto Ya hemos visto al pintor relacionado con su hermano Juan Velázquez y, de hecho, su aprendiz Gregorio Carballo se encuentra entre las personas cercanas a Velázquez y su familia, pues en octubre de 1647, tras la muerte de su maestro, actuó ante un escribano como testigo del pintor de cámara ${ }^{96}$.

Yanguas y Román tasan un total de sesenta y una pinturas, en su mayoría bocetos o borroncillos y estudios parciales. No obstante, algunas de estas pinturas también podrían ser ricordi de algunas de las obras que Ginete había ido realizando a lo largo de su carrera, y que quizá hubiesen tenido alguna significación especial para él. Así, los borrones para sendos retratos de un duque de Medina Sidonia, de su hijo y de su padre, que Ginete habría podido guardar por su condición de criado de la Casa. Al ser Yanguas y Román los tasadores de las pinturas, lo más probable es que se trate de retratos del titular de entonces, el duque don Gaspar, de su padre el VIII duque y de

\footnotetext{
${ }^{89}$ Sobre Puga: María Luisa Caturla, Antonio Puga, pintor gallego (La Coruña: 1982).

${ }^{90}$ Sobre Morán el Mozo: José Manuel Cruz Valdovinos, "Sobre el pintor de cámara Santiago Morán el Viejo (1571-1626)", Anales de Historia del Arte (2008), 171-187, 83. (1640).

${ }^{91}$ Madrid, RAH, 9-1071: Juan de Somarriba, Summa de la Aritmética reducida a la práctica universal

92 Vizcaíno, "El círculo", 1812.

93 AHP, P. 4842, ff. 220-223v.

${ }^{94}$ AHP, P. 4842, ff. 222v-223r.

${ }^{95}$ Agulló, Noticias, 28 y 183; Mercedes Agulló, Más noticias sobre pintores madrileños de los siglos XVI y XVIII (Madrid: 1981), 164 y 202; Aterido, Corpus, 59, 116 y 128; Vizcaíno, El pintor, 467.

96 Ángel Aterido, "La 'trastienda' del genio: Velázquez y su familia en la década de 1640", Archivo Español de Arte 283 (1998), 289-298, 292-293.
} 
su hijo el conde de Niebla y futuro yerno del valido Don Luis de Haro. En cualquier caso, en el taller dominan los retratos, lo que nos habla de una probable especialización de Ginete en este género. En primer lugar, encontramos uno de Felipe IV, una de las pocas pinturas terminadas presentes en el inventario ${ }^{97}$. De acuerdo con la descripción, el rey aparecía representado a caballo y armado en campaña. Se trata, sin duda, de una obra reciente, que probablemente presentaba al rey durante su intervención en las guerras de Cataluña, donde combatía el hijo del pintor. Encontramos también bocetos para retratos de Felipe III ${ }^{98}$ y de la reina Margarita ${ }^{99}$. Asimismo retratos para cortesanos, como un boceto para el retrato de Lorenzo Ramírez de Prado (1583-1658), alto funcionario que ocupaba puestos en el Consejo de Castilla y en el de la Inquisición. De Ramírez de Prado existe un retrato grabado por Philip Fruytiers (1610-1666) que podría basarse en el de Ginete (fig. 6). En el taller figuraba también el boceto para un retrato del Patriarca de las Indias, que Ginete podría haber realizado durante su anterior estancia en Madrid, quizá a raíz del nombramiento de Don Alonso en 1626. Resulta significativo que en la almoneda celebrada el 26 de marzo de 1647 el boceto fuese adquirido por Lázaro Díaz del Valle (1606-1669), para sí o por cuenta del propio Patriarca, de quien era criado. Años más tarde Díaz del Valle pudo haberse servido de este boceto para el retrato del Patriarca que incluyó en un manuscrito suyo fechado en 1656 pero en el que sigue trabajando al menos hasta $1661^{100}$. Se trata de un dibujo al carboncillo sobre papel recortado en forma de medallón y montado en un marco con diversas inscripciones, sobre el tercer folio ${ }^{101}$ (fig. 7). El Patriarca aparece representado con un aspecto que no parece corresponder a los sesenta y seis años que tenía en 1656, por lo que debe considerarse anterior a esa fecha. Aunque Valle debió de tener acceso frecuente al Patriarca desde 1626, como miembro de la capilla real y pudo por tanto haber realizado su retrato anteriormente, no es imposible que este dibujo se base en el borroncillo de Ginete.

También encontramos un retrato del padre alcantarino fray Francisco de Cogolludo (†1630), admirado por su santidad, que vivió en el convento real de San Gil en Madrid, uno de los principales centros de devoción de la Corte ${ }^{102}$. Este retrato de Ginete también podría estar en relación con otro grabado, esta vez de Juan de Noort $(† 1652)^{103}$, realizado para la publicación del sermón fúnebre que le dedicó el padre jesuita Francisco Pimentel en 1630 (fig. 8).

Con la venta y dispersión de estas obras se ponía discretamente punto y final a la carrera de este pintor cortesano caído desde entonces en el olvido. El que sus tareas

\footnotetext{
97 AHP, P. 4842, f. 225r.

98 AHP, P. 4842, f. 227v.

99 AHP, P. 4842, ff. 225r y 228r.

100 García López, Lázaro Díaz del Valle, ${ }^{79-82 .}$

101 García López, "Dibujo", 311.

102 Blas, de Carlos Varona y Matilla, Grabadores, 55.

${ }^{103}$ Blas, de Carlos Varona y Matilla, Grabadores, 481, n 649.
} 
como criado de la casa ducal lo tuvieran a menudo ocupado en labores ajenas a la pintura y el hecho de que la mayor parte de su obra conocida esté por identificar o haya sufrido gravemente el paso del tiempo, nos ha impedido valorar hasta ahora la importancia de este personaje. Los datos reunidos aquí nos muestran a Ginete como un pintor bien relacionado con las élites, al servicio tanto de los duques de Medina Sidonia, como de la colonia italiana en Madrid o de la propia familia real. Como hemos visto, su participación en los pleitos de las alcabalas y en la tasación del ciclo de El Paular lo muestra próximo de los pintores italianos del rey y de Velázquez.

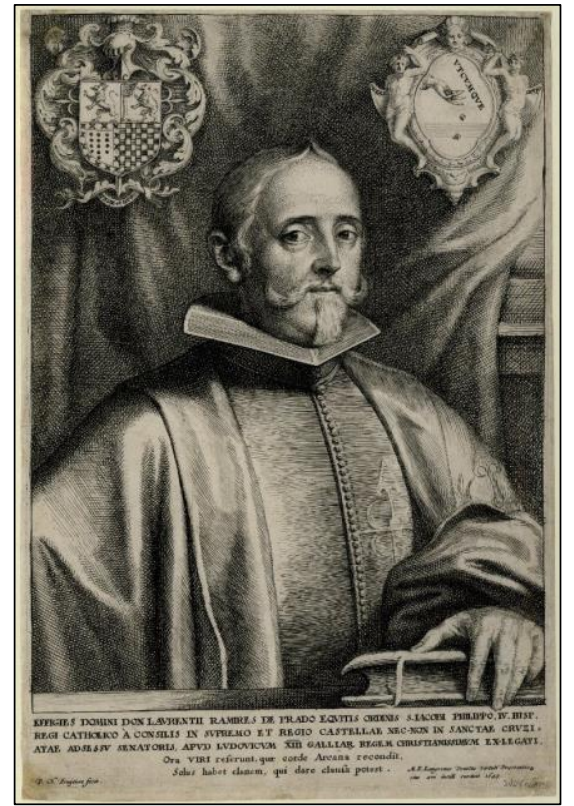

Fig. 6, Philip Fruytiers, Retrato de Lorenzo Ramírez de Prado. Madrid, Biblioteca Nacional de España.

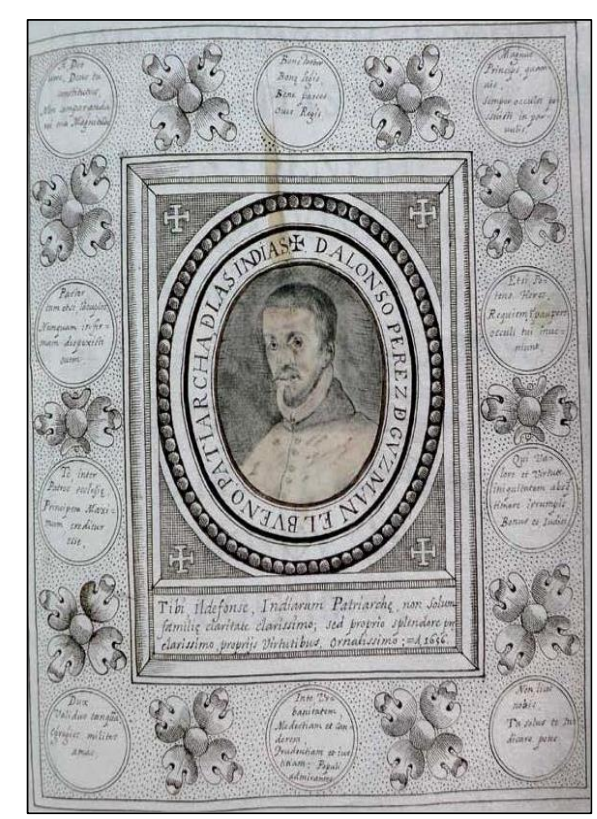

Fig. 7, Lázaro Díaz del Valle, Retrato del Patriarca de las Indias.Madrid, Real Academia de la Historia.

De su relativa fama en Madrid nos habla el que Lope de Vega cite su nombre en su pequeña dedicatoria. Incluso en la etapa final de su vida, cuando se pone su estrella con la estrepitosa caída de su protector el duque de Medina Sidonia, Ginete se nos aparece de nuevo cercano a los círculos cortesanos, y particularmente al de Velázquez y su familia a través de su aprendiz. No menos interesante resulta su labor como artista oficial de la corte ducal de Sanlúcar, al servicio de quienes fueron probablemente los señores más poderosos de la Monarquía Hispánica durante la primera mitad del siglo XVII. Su papel como intermediario entre Italia, Madrid y 
Andalucía deberá tenerse en cuenta en próximos estudios sobre el mecenazgo artístico de las cortes señoriales ${ }^{104}$.

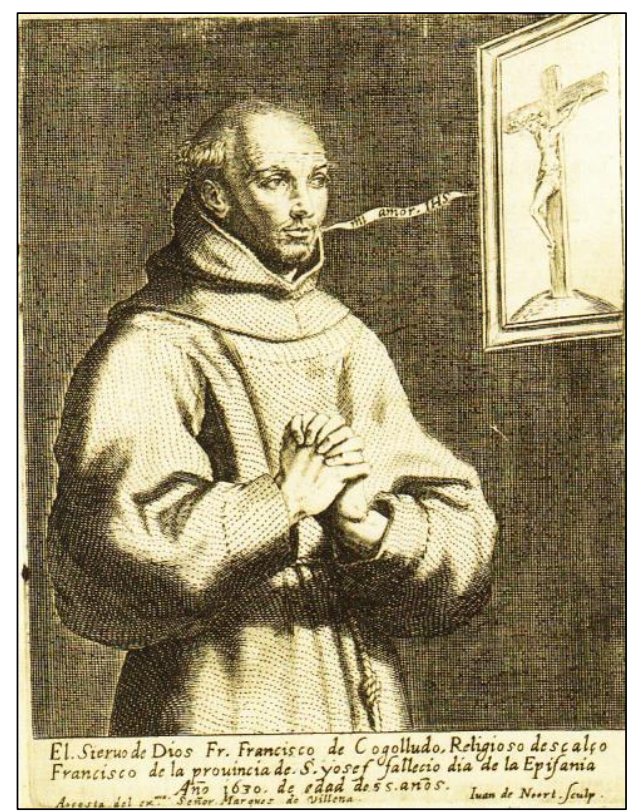

Fig. 8, Juan de Noort, Retrato de fray Francisco de Cogolludo. 1630, Madrid, Biblioteca Nacional de España.

\section{BIBLIOGRAFÍA}

Mercedes Agulló Cobo, Noticias sobre pintores madrileños de los siglos XVI y XVII, Granada 1978.

Mercedes Agulló Cobo, Más noticias sobre pintores madrileños de los siglos XVI y XVIII, Madrid ${ }^{1981}$.

${ }^{104}$ Los autores agradecen a J. L. Vega-Loeches (UCM), a F. Marías (UAM) y F. Bouza (UCM) por sus consideraciones sobre el texto, y a J. M. Cruz Valdovinos (UCM) por su amable colaboración, así como a L. Parejo (US) y al Rector del Santuario de la Caridad de Sanlúcar de Barrameda por la cortesía de cedernos parte de las imágenes, así como a la amabilidad del personal del Archivo Histórico de Protocolos de Madrid y al de la Fundación Casa Ducal de Medina Sidonia, en Sanlúcar de Barrameda. 
José Antonio Álvarez y Baena, Hijos de Madrid, ilustres en santidad, dignidades, armas, ciencias y artes, III, Madrid 1790.

Diego Angulo y Alfonso E. Pérez Sánchez, Pintura madrileña del primer tercio del siglo XVII, Madrid 1969.

Fausta Antonucci, "Virtud, pobreza y mujer (Vega Carpio, Lope Félix de): Dédicace", URL: $\quad$ http://www.idt.paris-sorbonne.fr/html/Vega-Virtud-Dedicace.html (consultado el 20/03/2014).

Fernando Arellano, El arte hispanoamericano, Caracas 1988.

Ángel Aterido Fernández, "La "trastienda" del genio: Velázquez y su familia en la década de 1640", in Archivo Español de Arte 283 (1998), 289-298. https://doi.org/10.3989/aearte.1998.v71.i283.708

Ángel Aterido Fernández, Corpus velazqueño. Documentos y textos, Madrid 2000.

Juan Luis Blanco Mozo, "Arte, crédito y usura: el pintor Francisco Gómez de la Hermosa y Giovanni Battista Crescenzi”, in Il mercato del credito in età moderna. Reti e operatori finanziari nello spazio europeo, ed. E. M. García Guerra/A. de Luca, Milano 2010, 163-180

Javier Blas, María Cruz de Carlos Varona y José Manuel Matilla, Grabadores extranjeros en la Corte española del Barroco, Madrid 2011.

Fernando Bouza, “Ardides del arte. Cultura de corte, acción política y artes visuales en tiempos de Felipe II”, in: Felipe II: un príncipe del Renacimiento, Madrid 1998

Fernando Bouza, Palabra e imagen en la corte. Cultura oral y visual de la nobleza en el Siglo de Oro, Madrid 2003.

Marcus Burke y Peter Cherry, Collections of paintings in Madrid: 1601-1755, Los Angeles 1997

Elvezio Canonica, "Lope y los literatos españoles en la corte de Felipe III", Anuario Lope de Vega 6 (2000), 61-73.

Clizia Carminati, "Marino e la Spagna nel Seicento", V. Nider, coor., Il prisma di Proteo. Riscritture, ricodificazione, traduzione fra Italia e Spagna (sec. XVI-XVIII), Trento 2012, 307-319.

María Luisa Caturla, Antonio Puga, pintor gallego, La Coruña 1982. 
Fernando Cruz Isidoro, El santuario de Ntra. Sra. de la Caridad de Sanlúcar de Barrameda, Córdoba, 1997.

Fernando Cruz Isidoro, "Francisco Juanete, pintor de cámara de la casa ducal de Medina Sidonia (1604-1638)", Laboratorio de arte 11 (1998), 435-460;

Fernando Cruz Isidoro, El convento sanluqueño de Capuchinos. Arte e bistoria de una fundación guzmana, Sanlúcar de Barrameda 2002.

Fernando Cruz Isidoro, "Aporte documental al mecenazgo artístico de los VII y VIII Duques de Medina Sidonia”, in Sanlúcar de Barrameda 42 (2006), 118-136.

Fernando Cruz Isidoro, El patrimonio restaurado de la basílica de la Caridad de Sanlúcar de Barrameda, Sanlúcar de Barrameda 2011.

José Manuel Cruz Valdovinos, "Aposento, alquileres, alcabalas, aprendices y privilegios (varios documentos y un par de retratos velazqueños inéditos)", in: $V$ Jornadas de arte Velázquezy y el arte de su tiempo, Madrid 1991, 91-108.

José Manuel Cruz Valdovinos, "Sobre el pintor de cámara Santiago Morán el Viejo (1571-1626)", Anales de Historia del Arte (2008), 171-187.

José Manuel Cruz Valdovinos, "El fuero y el huevo. La liberalidad de la pintura. Textos y pleitos", in Sacar de la sombra lumbre. La Teoría de la pintura en el Siglo de Oro 1560-1724, Madrid 2012, 173-202.

Félix Delgado López, "Juan de Baeza y las pinturas de Vicente Carducho en la cartuja del Paular”, Locus amoenus 4 (1998-1999), 185-200.

María del Mar Doval Trueba, Los "velazqueños": pintores que trabajaron en el taller de Velázquez, tesis doctoral dirigida por A. E. Pérez Sánchez, Universidad Complutense de Madrid, Madrid 2003.

Matías Fernández García, Parroquia madrileña de San Sebastián: algunos personajes de su archivo, Madrid 1995, 158-159.

David García López, Lázaro Díaz del V alle y las Vidas de pintores de España, Madrid 2008, 79-82.

David García López, “'Dibujo y divina poesía’: Lázaro Díaz del Valle, cronista real, genealogista y dibujante al servicio de Felipe IV”, in Goya 333 (2010), 308-319.

Carmen González Muñoz, "Datos para un estudio de Madrid en la primera mitad del siglo XVII", in Anales del Instituto de Estudios Madrileños 18 (1981), 149-186. 
Karin Hellwig, "Ut pictura sculptura: zu Velázquez’ Porträt des Bildhauers Montañés", in Zeitschrift für Kunstgeschichte 3 (1999), 298-319. https://doi.org/10.2307/1482953

José M. Hermoso Rivero y Antonio Romero-Dorado, "La Huerta del Desengaño de Sanlúcar de Barrameda, retiro y recreo del VIII duque de Medina Sidonia", in ElRincón malillo 4 (2014), 19-22.

Maria Kusche, Juan Pantoja de la Cruzy sus seguidores: B. González, $R$. de Villandrando y A. López. Polanco, Madrid 2007.

Manuel José de Lara Ródenas, "Los muros de Huelva: el conde de Niebla Manuel Alonso Pérez de Guzmán y su retiro en el castillo honubense", in El duque de Medina Sidonia, 2015, 309-310.

Celestino López Martínez, Notas para la Historia del Arte: arquitectos, escultores y pintores vecinos de Sevilla, Sevilla 1928.

Juan José Martín González, El artista en la sociedad española del siglo XVII, Madrid 1993

Antonio Matilla Tascón, "Comercio de pinturas y alcabalas”, in Goya 178 (1984), 180181.

David McGrath, "Lope as an icon", in A companion to Lope de Vega, ed. Alexander Samson/Jonathan Thacker, Woodbridge 2008, pp. 269-284.

Luis Méndez Rodríguez, “Un pintor ennoblecido: 'la nobleza y lustroso linaje' de los padres de Velázquez", in Laboratorio de arte 12 (1999), 125-134.

Javier Portús, Pintura y pensamiento en la España de Lope de Vega, Hondarribia 1999.

Elena Postigo Castellanos, Honor y privilegio en la Corona de Castilla: el Consejo de Ordenes y los caballeros de hábito en el s. XVII, Valladolid 1988.

Rafael Ramírez de Arellano, Inventario monumental y artístico de la provincia de Córdoba, Córdoba 1983.

Antonio Romero Dorado, "Fuegos artificiales en Doñana para Felipe IV y Olivares: Guzmán el Bueno y la sierpe de Fez. En torno al ideal ético y al repertorio estético de la casa de Medina Sidonia", in Cartare, 5 (2015), 31-64.

Luis Salas Almela, "La agencia en Madrid del VIII duque de Medina Sidonia, 16151636", in Hispania: revista española de historia 227 (2006), 909-958. https://doi.org/10.3989/hispania.2006.v66.i224.25

Luis Salas Almela, Medina Sidonia. El poder de la aristocracia, 1580-1670, Madrid 2008. 
André Turcat, Etienne Jamet alias Esteban Jamete, sculpteur français de la Renaissance en Espagne condamné par l'Inquisition, Paris 1994.

Antonio Urquízar Herrera, "Las casas del desengaño, sus animales, y los límites de las colecciones artísticas de los duques de Medina Sidonia en Sanlúcar de Barrameda", in El duque de Medina Sidonia: mecenazgo y renovación estética, ed. José Manuel Rico García/Pedro Ruiz Pérez, Huelva 2015, 97-118.

Lope de Vega, Parte veinte de las Comedias, Madrid 1627.

Juan Pedro Velázquez Gaztelu, Fundaciones de todas las iglesias, conventos y ermitas de la muy noble y muy leal ciudad de Sanlúcar de Barrameda, Sanlúcar de Barrameda 1995.

Juan Pedro Velázquez Gaztelu, Catálogo de todas las personas ilustres y notables de esta ciudad de Sanlúcar de Barrameda, ed. F. Cruz Isidoro, Sanlúcar de Barrameda 1996.

Cécile Vincent-Cassy, "Saint Michel et la Monarchie Hispanique : l'invocation de la protection angélique en 1643", in Des saints d'Etat, ed. Florence Buttay y Axelle Guillausseau, Paris 2012, 89-103.

María A. Vizcaíno, El pintor en la sociedad madrileña durante el reinado de Felipe IV, Madrid 2005.

María A. Vizcaíno, "El círculo de pintores italianos en la corte de Felipe IV", in José Martínez Millán, coor., Centros de poder italianos en la Monarquía Hispánica (siglos XVXVIII), Madrid 2010, 1797-1822.

Recibido: 31 de enero de 2018 Aprobado: 26 de marzo de 2018 